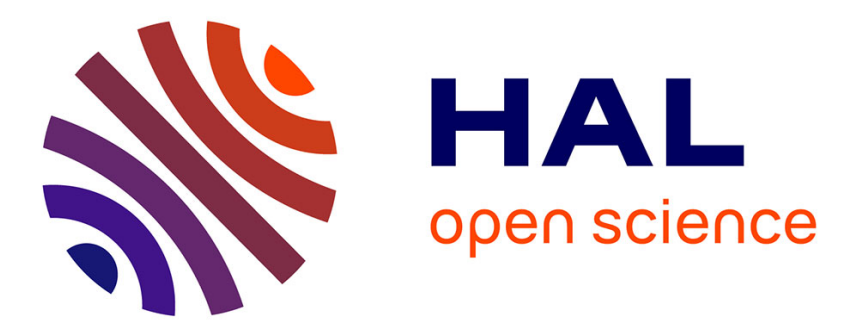

\title{
ATTENUATION OF WEAK SHOCK WAVES IN LIQUIDS
}

R. Smith, R. Stephens

\section{To cite this version:}

R. Smith, R. Stephens. ATTENUATION OF WEAK SHOCK WAVES IN LIQUIDS. Journal de Physique Colloques, 1972, 33 (C6), pp.C6-114-C6-116. 10.1051/jphyscol:1972625 . jpa-00215143

\section{HAL Id: jpa-00215143 https://hal.science/jpa-00215143}

Submitted on 1 Jan 1972

HAL is a multi-disciplinary open access archive for the deposit and dissemination of scientific research documents, whether they are published or not. The documents may come from teaching and research institutions in France or abroad, or from public or private research centers.
L'archive ouverte pluridisciplinaire HAL, est destinée au dépôt et à la diffusion de documents scientifiques de niveau recherche, publiés ou non, émanant des établissements d'enseignement et de recherche français ou étrangers, des laboratoires publics ou privés. 


\title{
ATTENUATION OF WEAK SHOCK WAVES IN LIQUIDS
}

\author{
R. T. SMITH and R. W. B. STEPHENS \\ Imperial College, London, Department of Physics, Grande-Bretagne
}

\begin{abstract}
Résumé. - Un transducteur électrodynamique est employé à la mesure de l'affaiblissement d'ondes de choc de faible intensité (pics de pression de 10 à 100 atmosphères) dans les lıquides. Toute comparaison de l'atténuation expérimentale et théorique doit, pour être satisfaisante, tenir compte du type d'onde envoyée dans le liquide, de l'écart à la planéité et de la forme particulière de la loi d'amortissement théorique supposée. Le pic expérimental des courbes de la pression en fonction de la distance montre une anomalie de la propagation caractérisée par une apparente augmentation de pression dans le liquide, effet qui est considéré comme semblable à celui observé par Eisenmenger (1964) au cours de mesures d'épaisseur du front de l'onde de choc. Les contrôles expérimentaux et les photographies de l'impulsion de pression suggèrent que l'anomalie de propagation est accompagnée dans le tube d'un écart à la condition de planéité pour l'onde produite par des vibrations de la membrane qui n'agit pas comme un piston.
\end{abstract}

Abstract. - An electrodynamic transducer has been used to generate weak shock waves (peak pressures 10-100 atmospheres) in liquids. Any valid comparison of experimental and theoretical attenuation is shown to depend on establishing the type of wave generated in the liquid, its deviation from planarity and the particular form of theoretical decay law assumed. The experimental peak pressure-distance plots showed an anomalous effect in the propagation characterised by an apparent increase of pressure in the liquid and this is considered to be a similar effect to that observed by Eisenmenger (1964) when measuring shock front thicknesses. Control experiments and photographs of the pressure pulse suggest that the anomalous propagation is accompanied by a breakdown of plane wave conditions in the tube produced by non-piston-like vibrations of the membrane.

1. Introduction. - Although the theory of weak shock propagation in fluids has been fairly well established [1-2] experimental confirmation of theory is beset by difficulties relating to the nature and form of the wave generated by the sound source itself and to the influence of the containing waveguide on the subsequent propagation. In the following paper, some problems are considered in connection with experimental work using an electrodynamic transducer generating pulses of about $4 \mu$ s duration and with peak pressures between 10-100 atm.

2. Simple theory. - For sawtooth, $N$ waves or single shock pulses propagating in fluids, the quasipermanent form of the wave can only be maintained by a diminution in peak amplitude related directly to the non-linear distortion behind the front of the shock [3]. This enables simple expressions for attenuation to be derived based on geometrical considerations as follows :

$$
\begin{array}{ll}
\alpha_{s}=\frac{2\left(1+\frac{B}{2 A}\right)}{\lambda c_{0}} u & \text { sawtooth waves } \\
\alpha_{N}=\frac{\left(1+\frac{B}{2 A}\right)}{\lambda_{N} c_{0}} u \quad N \text { waves } \\
\alpha_{p}=\frac{\left(1+\frac{B}{2 A}\right)}{2 l c_{0}} u \quad \text { single pulse }
\end{array}
$$

where $u$ is the peak particle velocity in the shock front, $c_{0}$ the small amplitude sound velocity, $B / A$ a parameter relating to the rate of change of compressibility with pressure for a liquid [3A], $\lambda$ the sawtooth wavelength (constant), $\lambda_{N}$ the $N$ wavelength (variable) and $l$ the pulse length. The expressions do not contain any parameter relating to dissipative processes (e. g. viscosity). Blackstock has shown that eq. (1a), (1b) can be derived as limiting solutions of more exact analytical expressions based on the basic hydrodynamic equations. Eq. (1c) will be used as a basis for comparison with experiment in the present work.

3. Experimental work. - 3.1. THE ELECTRODYNAMIC TRANSDUCER. - This is a device consisting of a $5 \mathrm{~cm}$ diameter flat copper coil of approximately 50 turns separated from a $5 \mathrm{~cm}$ diameter $\times 0.25 \mathrm{~mm}$ thick copper disc by a thin insulating film (Fig. 1a). When a high voltage capacitor is discharged through the coil the interaction of the inducing and induced electromagnetic fields produce a strong repulsion between the coil and the disc. Fuller experimental details of such a transducer have been given by Eisenmenger [4].

\subsection{EXPERIMENTAL ARRANGEMENT FOR ATTENUATION} MEASUREMENT. - In a practical arrangement (Fig. 1 $b$ ) the transducer is attached to the bottom of a vertical mild steel tube (about $1.2 \mathrm{~m}$ long, $5 \mathrm{~cm}$ bore with $2.5 \mathrm{~cm}$ thick walls) filled with liquid and sealed at the top end with a brass plate. The brass plate contains 


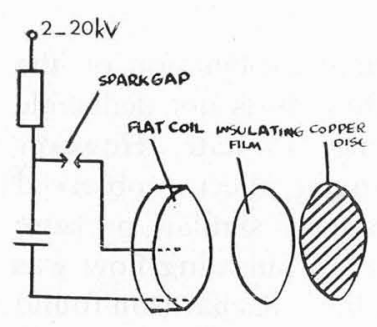

$a$

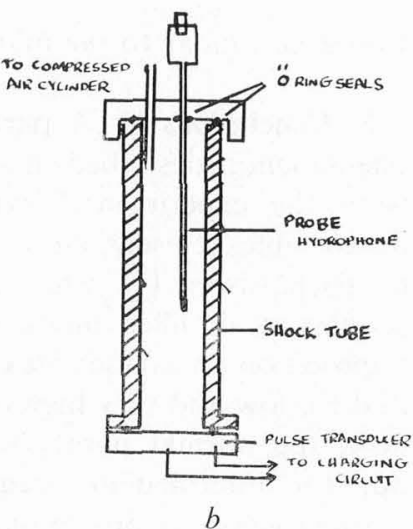

FIG. 1a. - Schematic arrangement of pulse transducer and high voltage charge/discharge circuit.

FIG. 1b. - Pulse transducer attached to bottom of vertical shock tube.

penetrations to accommodate a probe hydrophone and a means of applying a static pressure to the liquid of about $2 \mathrm{~atm}$ (in order to minimise flexure of the thin copper disc under the high impulsive stresses).

3.3. THE PRORE HYDROPHONE. - The probe hydrophone used for measuring peak shock pressures in the liquid consisted of a thin PZT4 (Lead Zirconate Titanate) crystal mounted in such a way that its thickness is perpendicular to the direction of travel of the shock. Redwood [5] has considered the response of such a transducer to pressure steps. The shock leading edge is reproduced as a voltage " ramp» function with a rise time corresponding to $X / v$ where $X$ is the crystal thickness in the direction of travel and $v$ is the velocity of compressional waves in the crystal. For a $1 \mathrm{~mm}$ thick crystal $X / v$ corresponds to a time of about $0.25 \mu \mathrm{s}$. Provided suitable matching of the crystal to its backing medium is achieved, faithful reproduction of the shock pulse is obtained. In practice, the PZT4 crystal ( $3 \mathrm{~mm}$ diameter $\times 1 \mathrm{~mm}$ thick) was bounded to a brass cylinder of the same diameter using a conducting cement; the crystal/cylinder assembly was in turn fitted into a $3 \mathrm{~mm}$ diameter stainless steel tube (about $80 \mathrm{~cm}$ long) via an insulating plug of tufnol.

4. Experimental results. - 4.1. AttenUation. Figure 2 shows the decay of peak pressure with distance for shock pulses of different initial pressure amplitudes in degassed distilled water. In each case, the decay is characterised by a region in which the pressure increases at a certain distance from the face of the transducer which decreases with increase of initial pressure. The attenuation of peak pressure $\alpha=1 / p(\mathrm{~d} p / \mathrm{d} x)$ computed from the measured slope of the $11 \mathrm{kV}$ plot in figure 2 (i. e. before the anomalous pressure increase occurs) is shown in figure 3 along side the theoretical values for the single pulse (eq. (1c)).

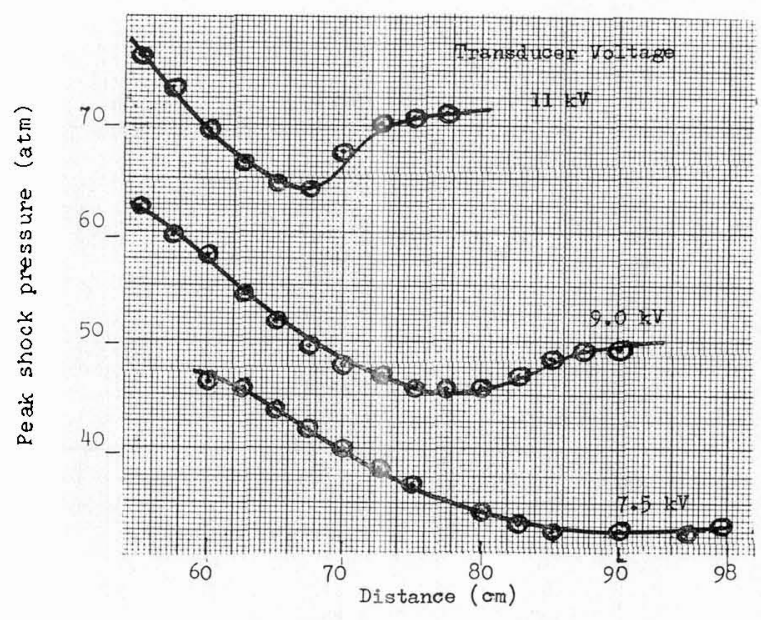

FIG. 2. - Decay of peak shock pressure in distilled water with distance from face of pulse transducer.

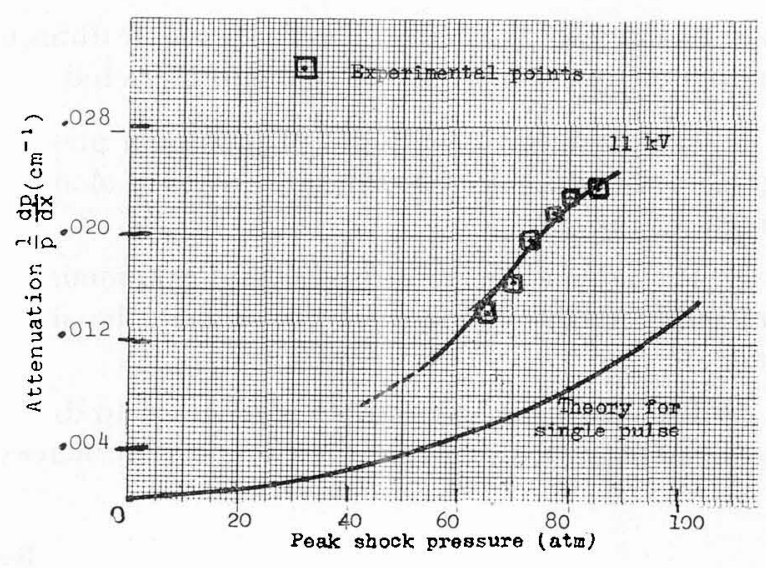

FIG. 3. - Comparison of experimental and theoretical peak shock attenuation for distilled water.

The experimental value of attenuation is higher than the theoretical by as much as a factor of two, whereas wall losses can be shown to represent less than $10 \%$ of the total wave attenuation (for calculation of wall losses, [6]. Even though part of this remaining discrepancy could be attributed to inaccuracies in hydrophone calibration and measurement of pulse length, increased attenuation above the theoretical value is more likely to arise both from distortion of the assumed plane wave profile and acoustic streaming at the high pressure amplitudes produced by the transducer.

4.2. ANOMAlous Region of pressure Change. In order to investigate the region of anomalous pressure rise, profiles of the peak pressure across the tube diameter were obtained at various distances from the face of the transducer. Such a set of measurements is shown in figure 4 where it is evident that plane wave conditions no longer apply beyond the point of mini- 


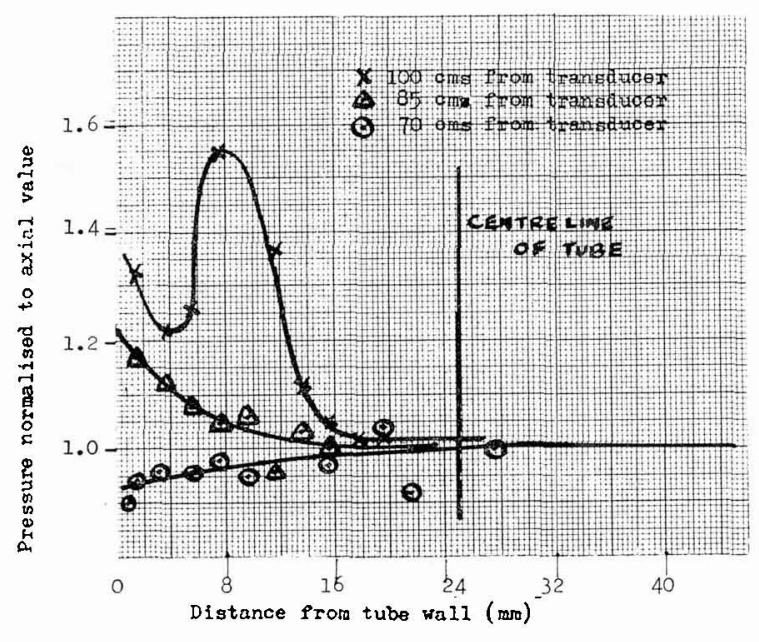

Fig. 4. - Distortion of the shock pressure profile (radial) across the tube diameter at various distances from the transducer.

mum pressure in the decay. The particular features of this anomalous region may be summarised as follows :

1) The distance to the point of minimum pressure in the axial decay is reduced with increase of initial pressure (Fig. 2).

2) The rate of pressure rise beyond this minimum pressure tends to be greater the higher the initial pressure.

3) The radial pressure profile was shown to distort even before the occurrence of the axial pressure increase (i. e. the profile just before the axial pressure increase would be similar to the middle curve of figure 4 ).

5. Conclusions. - A particular explanation of the phenomenon described in section $4 b$ is not deducible from the experimental evidence to date. However it resembles closely an " annular effect " observed by Richardson [7] who obtained similar pressure profiles in air filled tubes when a pulsating flow was imposed on an existing steady flow. Richardson found that for low and very high frequencies of the pulsating flow, the normal parabolic pressure profile applied, but for intermediate frequencies the pressure (or particle velocity) profile showed a steep rise towards the tube wall characteristic of turbulent flow.

In the shock tube experiments described in this paper there is certainly evidence of a strong acoustic streaming occurring (at very high pressure amplitudes, the water is forced out of the end of the open tube in a characteristic spout effect). A small pulsating flow could arise from oscillations of the tube wall or from secondary pressure fluctuations produced by the thin copper disc. Examination of the disc after repeated pulsing operations reveals two or three distinct nodal circles indicating that the vibrations are «nonpiston-like" and that flexure of the disc is occurring (with subsequent radial variations of pressure).

Eisenmenger [8] has observed similar anomalies using this transducer when measuring shock front thicknesses in liquids. Finally, although the results presented here are for water only, data is also available showing similar effects for various other liquids.

\section{References}

[1] Blackstock D. T., J. Acoust. Soc. Am. 36 (1964) 534.

[2] Blackstock D. T., J. Acoust. Soc. Am. 39 (1966) 1019.

[3] Landau and Lifshitz, Fluid Mechanics Pergamon Press (1959).

[3A] Bexer R. T., Physical Acoustics Vol. II B, Academic Press (1965) 231.
[4] Eisenmenger W., Acustica 12 (1962) 185.

[5] Redwood M., J. Acoust. Soc. Am. 33 (1961) 527.

[6] Temkins S., J. Acoust. Soc. Am. 46 (1969) 267.

[7] Richardson E. G., Dynamics of Real Fluids, Arnold (1950), 40.

[8] Eisenmenger W., Acustica 14 (1964) 187. 